\title{
Library Consortia in Nigeria and the Place of ICT
}

\author{
Idiegbeyan-ose Jerome \\ Covenant University, Nigeria \\ Ugwunwa Esse \\ Covenant University, Nigeria \\ Egbe Adewole-Odeshi \\ Covenant University, Nigeria
}

\section{INTRODUCTION}

Library Consortia implies the coming together of two or more libraries in a formal agreement to share their resources. The essence is that no library can boast of acquiring all the published literature in the world to render effective and efficient services for their users.

Islam (2013) cited Manan (1998) and explained that libraries have been cooperating and collaborating on collection building for many years, he further stressed that the aim of library consortia is to maximize the availability of and access to information and service at a minimum cost, consortia enables the participating libraries to leverage shrinking budget, learn from each others, build better tools together and serve their users better by taking advantage of one another's collection (Borek, 2006).

Obaro (2013) opines that resources sharing or Library consortia is a vital practice in every library especially academic libraries, this is as a result of the fact that no library can boast of self sufficiency; also knowledge has continued to grow over the years due to the high rate at which researches are conducted and their findings published for the purpose of educating people. Knowledge is growing at a geometric progression.

The need for access to information to support academic activities in institution is so high that a single library cannot afford it due to finance, manpower, and space. As a consequence of the perception of this situation, libraries started organizing networks and consortia with the aim of resource sharing. Collaborative efforts among and between libraries have been documented as far back as the late 19th century.
Academic library consortia in the United States have existed for multiple decades, having gained momentum in the 1970s with the development of shared catalogs and then having moved full speed into the shared purchases of electronic resources in the 1990s. Several library and information science (LIS) authors have covered consortia history and development, notably Weber (1976), Alexander (1999), Kopp (1998), and Bostick (2001) as cited by Chadwell (2011). The longevity or persistence of consortia speaks to their success. It also sets the stage for arguing that if academic libraries must adjust to a new climate focused on assessment and accountability, then consortia and other partnerships in which academic libraries participate must consider seriously how they might demonstrate their value more effectively.

In other words library consortium as a generic term is used to indicate any group of libraries working together towards a common goal whether to expand co-operation on traditional library services in the area of collection development or electronic information services. However, the common thing of all the definitions and consequently the subject matter is the coming together of libraries having common interest, needs and purposes to achieve a common goal that is beyond what an individual library can achieve on its own (Okeagu and Okeagu. 2008).

Consortium is further defined as an association of independent libraries and/or library systems established by formal agreement usually for the purpose of resource sharing. Membership may be restricted to a specific geographical region, type of library (academic, public, school) or subject specialization. The term consortium,

DOI: $10.4018 / 978-1-4666-5888-2 . c h 479$ 
networking, resource sharing, co-operation and partnerships are used inter-changeably to refer to strategic alliances amongst libraries with the aim of meeting the demands of clients for services that are delivered faster and reliably (Nwegbu, Echezona, and Obijiofo 2011).

\section{BACKGROUND}

library consortium is a group of two or more libraries that have agreed to cooperate with each other in order to fulfil certain similar needs, usually resource sharing. Cooperation among libraries which is not a new concept according to Sanni and Igbafe (2004) is an imperative for resources sharing and networking among libraries for the provision of qualitative library services especially in Nigeria being a developing nation like other African countries where development is in a very abysmal state. Traditionally, library cooperation meant sharing collection in some ways but is could as well include sharing of services, or of processes such as joint cataloguing of materials, or staff and user training.

Breeding (2013) is of the view that the key principle of resource sharing, centers on enabling libraries to provide access for their patrons to materials beyond their immediate local collection. Some involve reciprocal agreements where libraries make some or all of their collections available on request to patrons affiliated with cooperative partner institutions; others, where libraries or other organizations supply materials for a fee. Technology plays an essential role in support of resource sharing. Libraries depend on various types of automation systems to manage their collections, and other layers of infrastructure are needed to enable broader exchange of resources among libraries and their patrons.

In this age of information explosion, there is no library however big it may be, that has all it takes to satisfy all the needs of its users and this is due to various constraints. Okeagu and Okeagu (2008) submitted that African libraries have realized that no matter how they are well funded, it is still very difficult to acquire all the materials needed by their patrons. In view of this fact, partnership and co-operation at local, national and international levels have become inevitable for all libraries. Townley (1992) in his work on college library consortia in the United States of America acknowledged that a college library alone cannot afford enhanced collections in more than a few subject areas but by banding together, college library collections can form a virtual research library to the benefit of faculty and students at all participating institutions. The concept of library consortium has developed as a result of the aspirations of libraries to reach out to more users and to satisfy their information needs from time to time. Consortium of libraries is well known for sharing of resources all over the world. Information explosion, emergence of Internet and particularly World Wide Web as a new medium of information storage and gateway makes the consortium of libraries come more into sight than before.

\section{MAIN FOCUS OF THE ARTICLE}

\section{History of Library Consortia}

According to Folorunso and Folorunso (2010) there is no particular date that can be cited as the beginning point of library consortium, the concept of consortium as an association or partnership has long been a tenet of librarianship. Consortia (p1ural) or consortium (singular) literarily means fellowship. Homogeneously, the term "consortia" can be translated to mean alliance, collaboration, co-operation or partnership. A library consortium is a group of two or more libraries that have agreed to cooperate with each other in order to fulfil certain similar needs, usually resource sharing.

\section{Library Consortia in Africa}

Alema and Antwi (2002) submitted that the most vigorous and successful development of library consortia has occurred in South Africa. While there were some cooperative library initiatives prior to 1990 , it was during the period from 1992 to 1999 that saw the most significant advances, although some consortia may have been more "conceptual" and less operational. A study completed in 2002 shows that by the turn of the century, however, there were only a few functioning consortia in Africa, this despite serious efforts among African universities in particular to foster library cooperation through the Association of African Universities (AAU) and with support of the International Development Research Center. Examples of such are South African Bibliographic and Information Network (SABINET), CAPE Libraries Cooperatives (CALICO), Eastern 
7 more pages are available in the full version of this document, which may be purchased using the "Add to Cart" button on the product's webpage: www.igi-global.com/chapter/library-consortia-in-nigeria-and-the-place-ofict $/ 112933$ ?camid $=4 \mathrm{v} 1$

This title is available in InfoSci-Books, InfoSci-Computer Science and Information Technology, Science, Engineering, and Information Technology, InfoSci-Select, InfoSci-Select, InfoSci-Select. Recommend this product to your librarian:

www.igi-global.com/e-resources/library-recommendation/?id=1

\section{Related Content}

Classification of Polarity of Opinions Using Unsupervised Approach in Tourism Domain Mahima Goyal and Vishal Bhatnagar (2016). International Journal of Rough Sets and Data Analysis (pp. 68-78).

www.igi-global.com/article/classification-of-polarity-of-opinions-using-unsupervised-approach-intourism-domain/163104?camid=4v1a

An Experimental Sensitivity Analysis of Gaussian and Non-Gaussian Based Methods for Dynamic Modeling in EEG Signal Processing

Gonzalo Safont, Addisson Salazar, Alberto Rodriguez and Luis Vergara (2015). Encyclopedia of Information Science and Technology, Third Edition (pp. 4028-4041).

www.igi-global.com/chapter/an-experimental-sensitivity-analysis-of-gaussian-and-non-gaussianbased-methods-for-dynamic-modeling-in-eeg-signal-processing/112846?camid=4v1a

Exemplary Works on Information Systems Research

Michael E. Whitman and Amy B. Woszczynski (2004). The Handbook of Information Systems Research (pp. 1-14).

www.igi-global.com/chapter/exemplary-works-information-systems-research/30339?camid=4v1a Image Segmentation Using Rough Set Theory: A Review

Payel Roy, Srijan Goswami, Sayan Chakraborty, Ahmad Taher Azar and Nilanjan Dey (2014). International Journal of Rough Sets and Data Analysis (pp. 62-74).

www.igi-global.com/article/image-segmentation-using-rough-set-theory/116047?camid=4v1a 